\title{
elF4A3 is a novel component of the exon junction complex
}

\author{
CHIA C. CHAN, ${ }^{1}$ JOSÉE DOSTIE, ${ }^{1}$ MICHAEL D. DIEM, ${ }^{1}$ WENQIN FENG, ${ }^{1}$ MATTHIAS MANN, ${ }^{2}$ \\ JURI RAPPSILBER, ${ }^{2}$ and GIDEON DREYFUSS ${ }^{1}$ \\ ${ }^{1}$ Howard Hughes Medical Institute and Department of Biochemistry \& Biophysics, University of Pennsylvania School of Medicine, \\ Philadelphia, Pennsylvania 19104-6148, USA \\ ${ }^{2}$ Protein Interaction Laboratory, University of Southern Denmark, DK-5230 Odense M, Denmark
}

\begin{abstract}
The exon junction complex (EJC) is a protein complex that assembles near exon-exon junctions of mRNAs as a result of splicing. EJC proteins play important roles in postsplicing events including mRNA export, cytoplasmic localization, and nonsensemediated decay. Recent evidence suggests that mRNA translation is also influenced by the splicing history of the transcript. Here we identify eIF4A3, a DEAD-box RNA helicase and a member of the elF4A family of translation initiation factors, as a novel component of the EJC. We show that elF4A3 associates preferentially with nuclear complexes containing the EJC proteins magoh and Y14. Furthermore, elF4A3, but not the highly related elF4A1 or elF4A2, preferentially associates with spliced mRNA. In vitro splicing and mapping experiments demonstrate that eIF4A3 binds mRNAs at the position of the EJC. Using monoclonal antibodies, we show that eIF4A3 is found in the nucleus whereas eIF4A1 and eIF4A2 are found in the cytoplasm. Thus, elF4A3 likely provides a splicing-dependent influence on the translation of mRNAs.
\end{abstract}

Keywords: eIF4A3; exon junction complex; RNA helicase; splicing; translation

\section{INTRODUCTION}

As nascent transcripts, pre-mRNAs are associated with abundant nuclear proteins collectively known as hnRNP proteins (Choi and Dreyfuss 1984; Dreyfuss et al. 1993). Pre-mRNA processing in the nucleus includes addition of a cap structure, splicing, and polyadenylation, and is accompanied by changes in the composition and arrangements of proteins associated with the mRNA (Dreyfuss et al. 2002). Recently, pre-mRNA splicing was shown to be accompanied by a profound change in the protein composition of the mRNA (Luo and Reed 1999; Kataoka et al. 2000; Le Hir et al. 2000b). In particular, mRNAs generated by splicing acquire specific protein complexes that assemble 20 to 24 nt upstream of spliced junctions, termed the exon junction complex (EJC; Kataoka et al. 2000, 2001; Le Hir et al. 2000a, 2001; Zhou et al. 2000; Kim et al. 2001a; Luo et al. 2001).

Reprint requests to: Gideon Dreyfuss, Howard Hughes Medical Institute and Department of Biochemistry \& Biophysics, University of Pennsylvania School of Medicine, Philadelphia, Pennsylvania 19104-6148, USA; e-mail: gdreyfuss@hhmi.upenn.edu; fax: (215) 573-2000.

Article and publication are at http://www.rnajournal.org/cgi/doi/ 10.1261/rna.5230104.
The known proteins of the EJC, SRm160, RNPS1, UAP56, Aly/REF, Upf3, Y14, and magoh, function at many levels during mRNA metabolism. SRm160 and RNPS1 are activators of pre-mRNA splicing (Blencowe et al. 1998; Mayeda et al. 1999), whereas Aly/REF and UAP56 were shown to function in the nuclear export of mRNAs (Zhou et al. 2000; Gatfield et al. 2001). RNPS1 (Lykke-Andersen et al. 2001), hUpf3 (Lykke-Andersen et al. 2000), and Y14 (Gehring et al. 2003) were shown to play a role in nonsensemediated decay (NMD) of mRNAs, a process that leads to degradation of mRNAs containing premature termination codons. Y14 along with its associated protein magoh were also shown to be important for oskar mRNA localization in Drosophila during oogenesis (Newmark and Boswell 1994; Hachet and Ephrussi 2001; Mohr et al. 2001). In addition, the EJC may be important for translation efficiency. The observation that the presence of an intron can enhance translation efficiency of some mRNAs (Matsumoto et al. 1998; Nott et al. 2003; Wiegand et al. 2003) and the finding that most EJC proteins bind spliced but not intronless mRNAs (Dreyfuss et al. 2002) suggests that the EJC may be involved in increasing translation efficiency of spliced mRNAs. Thus, the fate of processed mRNAs is partly influenced by the acquisition of the EJC. In addition to pro- 
viding information about the overall structure of the gene from which the mRNA is produced, EJC proteins could determine the path through which mRNAs are processed from their precursors and possibly provide additional signals (Dreyfuss et al. 2002).

Among the components of the EJC, magoh and Y14 are of considerable interest because they persist on mRNAs after export from the nucleus to the cytoplasm, where they are removed by the translation machinery (Dostie and Dreyfuss 2002). Therefore, the identification of proteins that associate with Y14 and magoh or the complexes that contain them is of particular importance in studying the function of the EJC in postsplicing events. Here, we identify eIF4A3 as a novel component of the EJC. We show that eIF4A3, a member of the eIF4A DEAD-box helicase family of

\section{Immunoprecipitation with anti-flag}

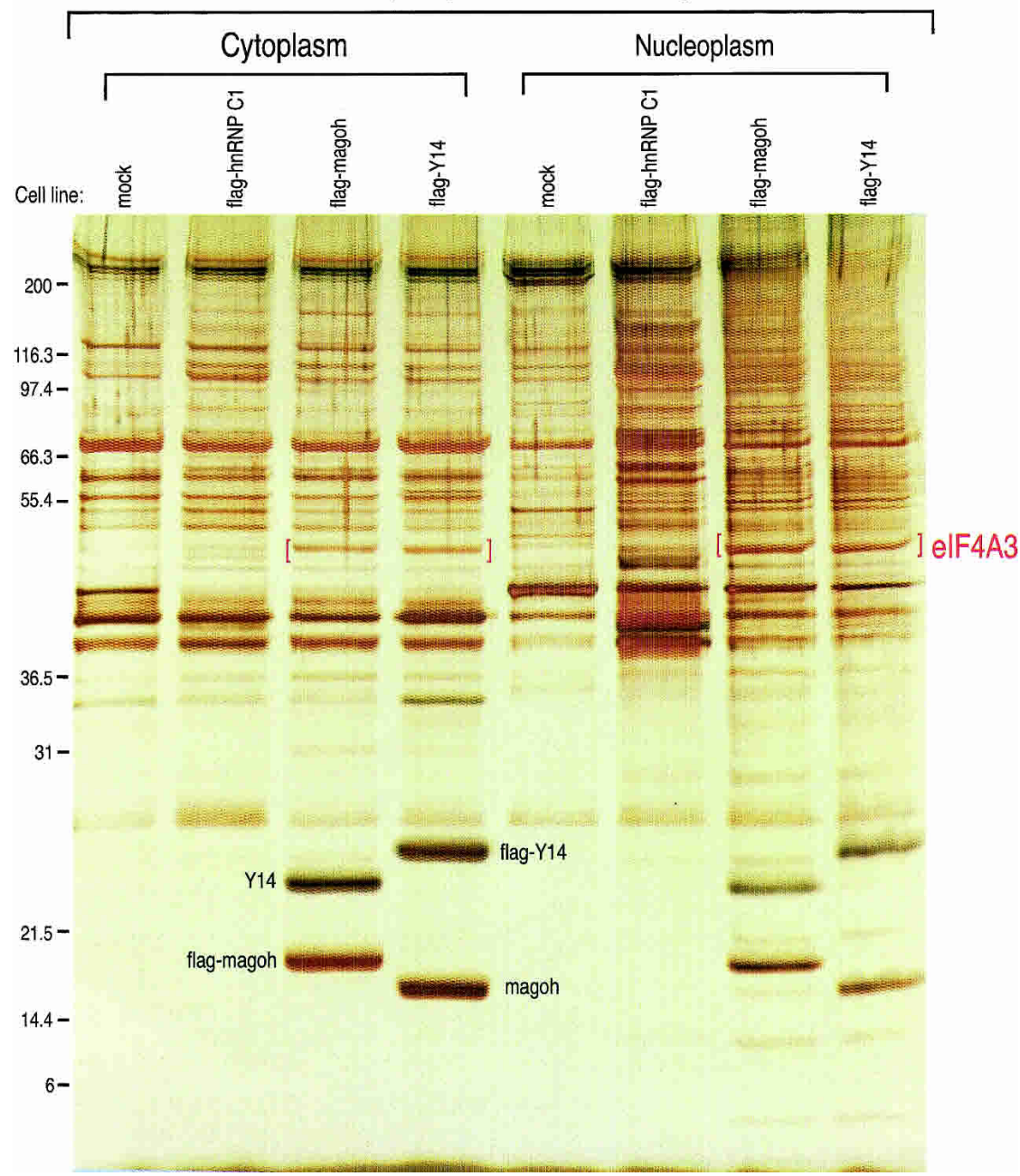

FIGURE 1. Identification of eIF4A3 as a flag-magoh and flag-Y14 complex associated protein in vivo by mass spectrometry. Nucleoplasmic (right) and cytoplasmic (left) extracts from parental Tet-On (mock), flag-hnRNP C1, flag-magoh, and flag-Y14 cell lines were incubated with anti-flag antibody beads and bound proteins were eluted as described in Materials and Methods. Eluted proteins were resolved by SDS-PAGE and detected by silver staining. The protein migrating with an apparent molecular weight of $47 \mathrm{kD}$ was identified by mass spectrometry as eIF4A3. translation initiation factors, binds spliced but not intronless mRNAs. Furthermore, eIF4A3 associates with spliced mRNAs at the position of the EJC. We suggest that eIF4A3 may provide a link between splicing and translation in the cytoplasm.

\section{RESULTS}

\section{Mass spectrometry identifies eIF4A3 as a protein that associates with magoh and Y14 complexes}

To facilitate the characterization of the EJC, we generated tetracycline-inducible stable cell lines that express flagtagged magoh, flag-tagged Y14, and, as a control, flagtagged hnRNP C1 (Fig. 1). To allow proper incorporation of the tagged proteins without disruption of the endogenous complexes, cell lines were established and characterized under conditions where low levels of the tagged proteins were expressed. Proteins that associate with Y14- and magoh-containing complexes were identified by immunoprecipitation with anti-flag antibody (M2) from both the cytoplasmic and nucleoplasmic fractions. Proteins bound to the anti-flag antibody beads were eluted with flag peptides, resolved by SDSPAGE, and detected by silver staining. Proteins that associated with magoh- or Y14-containing complexes but not with hnRNP C1 complexes were isolated from the gel and identified by nanoelectrospray mass spectrometry. Two peptide sequences were identified for the 47$\mathrm{kD}$ protein band (Fig. 1). The first peptide sequence, GIYAYGFEKPSAIQQR, is found in eukaryotic initiation factors eIF4A1, eIF4A2, and eIF4A3, whereas the second peptide sequence, LDYGWHVV AGTPGR, is found only in eIF4A3 (Fig. 2 ). Therefore, these peptides uniquely identify eIF4A3 as part of the $47-\mathrm{kD}$ protein band coimmunoprecipitated with magoh and Y14 complexes.

\section{Monoclonal antibodies localize eIF4A3 to the nucleoplasm}

To confirm that eIF4A3 is a component of magoh- and Y14-containing complexes and to further characterize this association, monoclonal antibodies against recombinant eIF4A3 were generated. One antibody, designated 3F1, recognized a single protein band migrating 


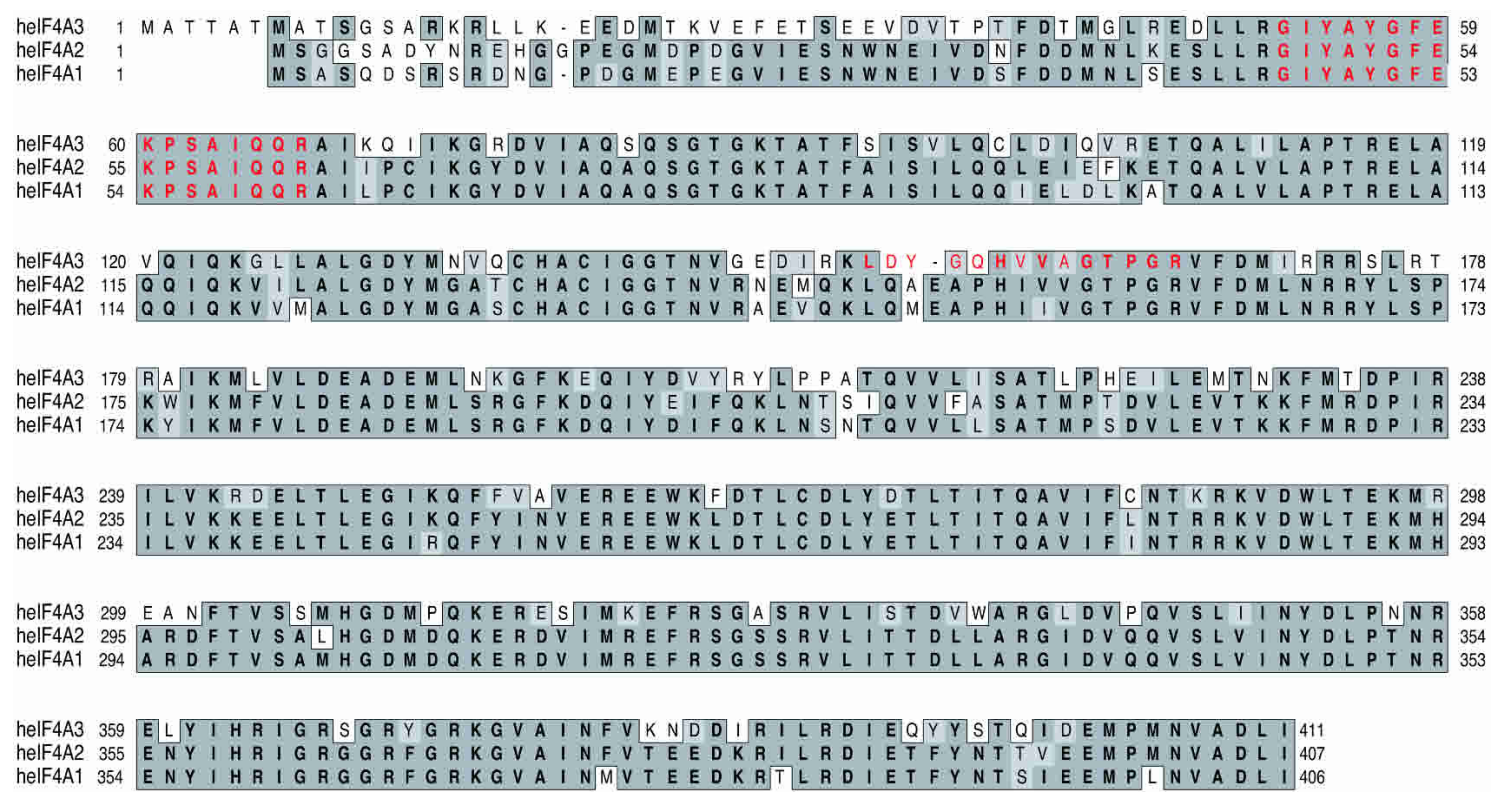

FIGURE 2. Amino acid sequence alignment of human eIF4A translation initiation factors. Human eIF4A3 (CAA56074), eIF4A2 (BAA06336), and eIF4A1 (P04765) amino acid sequences were aligned using the ClustalW alignment program. Identical and conserved residues are indicated by dark gray and light gray shading, respectively. Peptides identified by mass spectrometry are shown in red. The conserved DEAD-box RNA helicase domain extends from amino acids ca. 82 to 372 .

with an apparent molecular weight of $47 \mathrm{kD}$ by Western blotting (Fig. 3A). Because eIF4A3 shares 67\%-68\% identity and is of similar size to eIF4A1 and eIF4A2 (Fig. 2), we tested the specificity of $3 \mathrm{~F} 1$ on recombinant eIF4A3, eIF4A2, and eIF4A1. As shown in Figure 3B, 3F1 specifically recognized eIF4A3 by Western blotting. In addition, 3F1 specifically immunoprecipitated in vitro translated eIF4A3 but not in vitro translated eIF4A1 or eIF4A2 (Fig. 3C). Immunofluorescence microscopy on HeLa cells using 3F1 indicates that eIF4A3 primarly localizes to the nucleoplasm (Fig. 4). A similar localization pattern was observed for transiently transfected myc-eIF4A3. These results are in agreement with a previous study showing that eIF4A3 is a nuclear protein (Holzmann et al. 2000). In contrast, transiently transfected myc-eIF4A2 and myc-eIF4A1 localized to the cytoplasm. Although eIF4A3 predominantly localized to the nucleus by immunofluorescence, significant amounts were found in the cytoplasm by cell fractionation (Fig. 5, bottom panel).

\section{elF4A3 coimmunoprecipitates with nuclear magoh- and Y14-containing complexes}

To confirm that eIF4A3 is associated with magoh and Y14 complexes, the complexes were immunoprecipitated with anti-flag antibodies and analyzed by Western blotting with anti-eIF4A3 antibodies. Figure 5 shows that eIF4A3 efficiently coimmunoprecipitates with magoh and Y14 from the nucleoplasm but not with hnRNP C1. The preferential association of eIF4A3 with nuclear magoh and Y14 was not due to the presence of higher levels of the flag-tagged pro- teins in the nucleus, because higher amounts of flag-magoh and flag-Y14 were immunoprecipitated from the cytoplasmic fraction as compared to the nucleoplasmic fraction (Fig. 5). Also, the preferential coimmunoprecipitation of eIF4A3 with nuclear magoh and Y14 was not due to higher nuclear levels of eIF4A3 because considerable amounts of eIF4A3 were also found in the cytoplasm (Fig. 5, cytoplasmic input lane). Thus, these results demonstrate that eIF4A3 associates in vivo with magoh- and Y14-containing complexes and suggest that this association takes place predominantly in the nucleus.

Because eIF4A3 is highly similar in sequence to eIF4A1 and eIF4A2, it was possible that these proteins might also be associated with Y14 complexes. To determine whether eIF4A1 and eIF4A2 are associated with Y14-containing complexes, myc-eIF4A1, myc-eIF4A2, and myc-eIF4A3 were transiently transfected into either flag-Y14 or flaghnRNP C1 cell lines. Flag-Y14 and flag-hnRNP C1 were immunoprecipitated as described above and analyzed by Western blotting with anti-myc and anti-flag antibodies. In agreement with the results presented for the endogenous protein, myc-eIF4A3 was coimmunoprecipitated with nuclear flag-Y14 but not with flag-hnRNP C1. In contrast, myc-eIF4A2 was not coimmunoprecipitated with nuclear or cytoplasmic flag-Y14, whereas similar to myc-eIF4A3, low levels of myc-eIF4A1 coimmunoprecipitated with cytoplasmic flag-Y14 (data not shown). Together, these results demonstrate that eIF4A3 specifically associates with Y14-containing complexes in the nucleus and suggest that this interaction persists into the cytoplasm. 
A

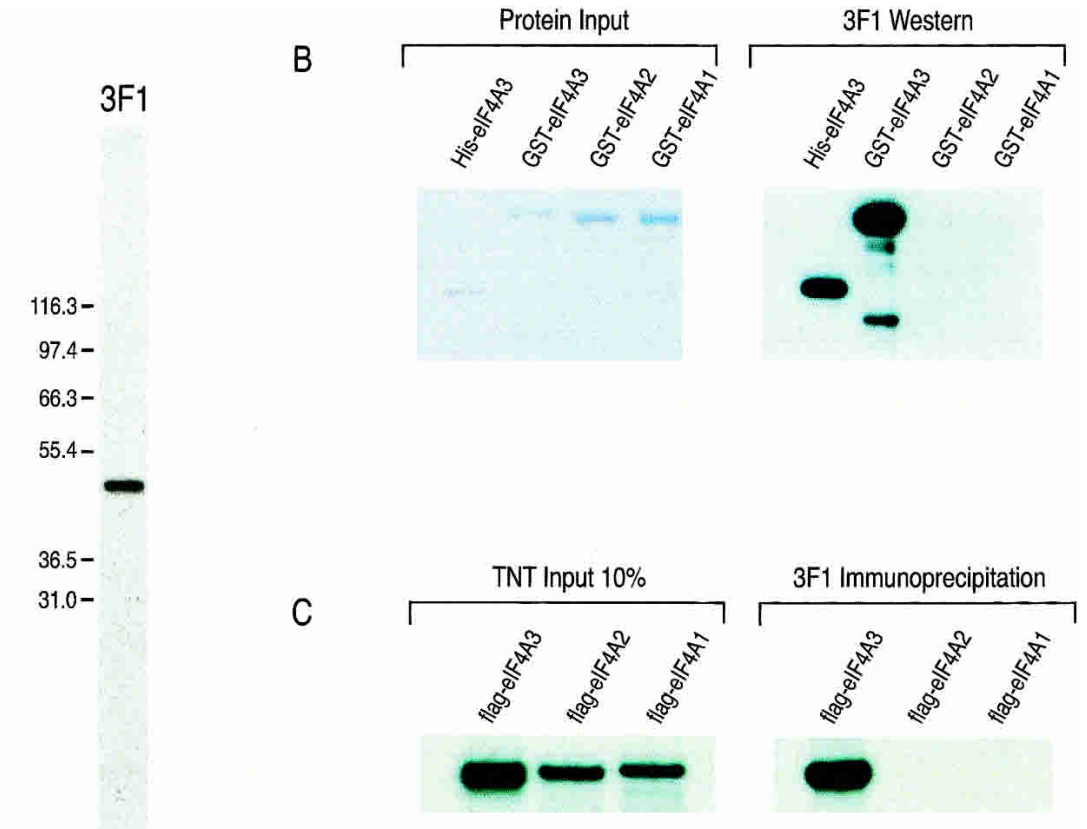

FIGURE 3. Characterization of the anti-eIF4A3 monoclonal antibody 3F1. (A) 3F1 recognizes a single band migrating at approximately $47 \mathrm{kD}$ by Western blotting on total HeLa cell extract. Molecular weight markers (in kilodaltons) are shown on the left. (B) $3 \mathrm{~F} 1$ specifically recognizes eIF4A3. Recombinant His-eIF4A3, GST-eIF4A3, GST-eIF4A2, and GST-eIF4A1 proteins were either stained with Coomassie (left panel, Protein Input) or transferred onto a nitrocellulose membrane and analyzed by Western blotting with 3F1 (right panel, 3F1 Western). (C) 3F1 immunoprecipitates eIF4A3 and not eIF4A1 or eIF4A2. Flag-eIF4A3, flageIF4A2, and flag-eIF4A3 were produced by in vitro transcription and translation in rabbit reticulocyte lysate in the presence of $\left[{ }^{35} \mathrm{~S}\right]$ methionine and immunoprecipitated with $3 \mathrm{~F} 1$. Bound proteins were resolved by SDS-PAGE and visualized by fluorography (right panel, 3F1 Immunoprecipitation). Input represents $10 \%$ of the amount used for immunoprecipitation (left panel, TNT Input 10\%).

\section{elF4A3 binds mRNAs produced by splicing but not intronless $\mathrm{mRNA}$}

Y14 and magoh were previously shown to be components of postsplicing, pretransport mRNPs and to preferentially associate with spliced mRNAs (Kataoka et al. 2000, 2001; Le Hir et al. 2000a). Because eIF4A3 associates with nuclear magoh- and Y14-containing complexes (Fig. 5), we asked whether eIF4A3 might also predominantly bind spliced mRNAs. To test this, we examined the binding of eIF4A3 to splicing products of a previously characterized pre-mRNA derived from the chicken $\delta$-crystallin $(\mathrm{CDC} 1)$ gene (Ohno et al. 1987). Splicing reactions were immunoprecipitated with antibodies against hnRNP C (4F4), Y14 (4C4), eIF4A3 (3F1), or with the nonimmune antibody SP2/0 as control, and associated RNAs were analyzed on a polyacrylamide denaturing gel. Similar to Y14, eIF4A3 preferentially associated with spliced but not intronless mRNAs, whereas premRNAs were predominantly coimmunoprecipitated with hnRNP C1 (Fig. 6). The association of eIF4A3 with spliced mRNAs is a general characteristic of this protein and not unique to the CDC RNA, as similar results were obtained with a splicing substrate derived from the adenovirus major late promotor ( $\mathrm{Ad} 2$; data not shown; Pellizzoni et al. 1998). These results demonstrate that eIF4A3 associates with spliced mRNAs.

\section{elF4A1 and elF4A2 do not bind spliced mRNAs}

In addition to sharing conserved motifs characteristic of the DEAD-box RNA helicases, eIF4A3 is $67 \%$ identical to eIF4A1, with most of the divergence residing in the first 40 amino acids of eIF4A3 (Li et al. 1999). Because of this high degree of sequence similarity, we asked whether eIF4A1 and eIF4A2 could also bind spliced mRNAs. To answer this question, splicing reactions made from total extracts of HeLa cells transiently transfected with flag-eIF4A1, flag-eIF4A2, or flag-eIF4A3 were immunoprecipitated with anti-flag antibodies and processed as described above (Fig. 6). In this assay, flag-eIF4A3 was predominantly bound to spliced mRNAs (Fig. 7, lane 4) but flageIF4A2 and flag-eIF4A1 were not (Fig. $7 \mathrm{~A}$, lanes 8,12). Because the amount of flag-eIF4A3, flag-eIF4A2, and flag-eIF4A1 proteins in each splicing extract was similar (Fig. 7B), the difference in binding to spliced mRNAs reflects an intrinsic characteristic of eIF4A3. Thus, eIF4A3 is the only eIF4A family member that has the capacity to bind spliced mRNAs in an in vitro splicing assay.

\section{elF4A3 binds at the position of the exon junction complex}

Y14 and magoh, as well as the other components of the EJC, bind mRNAs approximately at $21 \mathrm{nt}$ upstream of exonexon junctions. Because eIF4A3 associates in vivo with nuclear magoh and Y14 complexes and it preferentially binds to spliced mRNAs, we asked whether eIF4A3 is a component of the EJC. To determine the binding position of eIF4A3 on spliced mRNAs, we carried out an RNA mapping analysis as previously described (Le Hir et al. 2000a; Kataoka et al. 2001; Kim et al. 2001b). In this assay, in vitro splicing reactions using Ad2 pre-mRNA were incubated with recombinant RNase $\mathrm{H}$ and DNA oligonucleotides, which are complementary to mRNA sequences flanking the EJC site (A10 and A5 on Fig. 8). The reactions were then used in immunoprecipitation experiments with the indicated antibodies (Fig. 8A). As illustrated in Figure 8B, sev- 

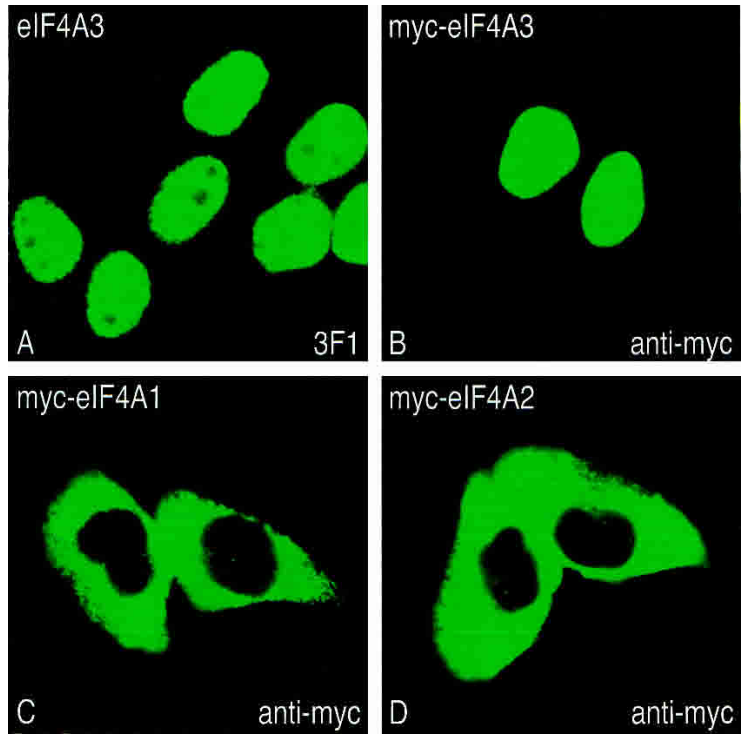

FIGURE 4. eIF4A3 localizes to the nucleoplasm by immunofluorescence. (A) Characterization of the localization of endogenous eIF4A3 in HeLa cells with anti-eIF4A3 antibody 3F1. Immunofluorescence analysis of transiently transfected myc-eIF4A3 $(B)$, myc-eIF4A1 $(C)$, and myc-eIF4A2 $(D)$ with anti-myc antibody $9 \mathrm{H} 10$.
Srm160 was tested, and hnRNP C1 and hnRNP A1 were used as controls. This experiment was also performed with GST alone to control for background (data not shown). As shown in Figure 9, eIF4A3 efficiently associates with the mRNA export factor TAP and with Aly/REF. In this assay, GST-eIF4A3 did not significantly bind to magoh or Y14 (binding less than 2\%), suggesting that eIF4A3, as a component of the EJC, associates with Y14 and magoh indirectly through its interaction with TAP and Aly/REF. The ability of GST-eIF4A3 to bind efficiently to in vitro translated TAP and Aly/REF was not shared by GST-eIF4A1 (Fig. 9).

\section{DISCUSSION}

The EJC is a multiprotein complex that contains proteins important in splicing and polyadenlyation (RNPS1, SRm160), mRNA export (UAP56, Aly/REF), NMD (Y14, RNPS1, Upf3), and mRNA localization (Y14, magoh). Through the use of inducible flag-Y14- and flag-magohexpressing cell lines, we identified eIF4A3 as a component of Y14 and magoh complexes, and demonstrated that it is a novel component of the EJC. eIF4A3 is a DEAD-box RNA helicase homologous to the translation initiation factors eral fragments were generated by the sequence-specific digestion of the $\mathrm{Ad} 2$ mRNAs with the oligonucleotides. The shortest fragment (F2) contains the 20-nt region upstream of the exon-exon junction and corresponds to the region where the EJC proteins are bound. Figure 8A shows that similar to Y14, eIF4A3 associates with the F2 fragment from the in vitro splicing reaction. Anti-cap antibody (H20), used as a control, did not immunoprecipitate the F2 fragment. Similar results were obtained from a mapping experiment performed with the CDC premRNA (data not shown). These findings indicate that eIF4A3, like Y14, magoh, and other EJC components, binds at the position of the exon junction complex and is therefore a bona fide EJC protein.

\section{elF4A3 binds TAP and Aly/REF in vitro}

Because eIF4A3 binds to spliced mRNAs at the position of the EJC, we asked whether eIF4A3 could interact with other known components of the EJC. For this, the binding of recombinant GST-eIF4A3 to in vitro translated magoh, Y14, Aly/ REF, TAP, Upf3a, RNPS1, UAP56, and

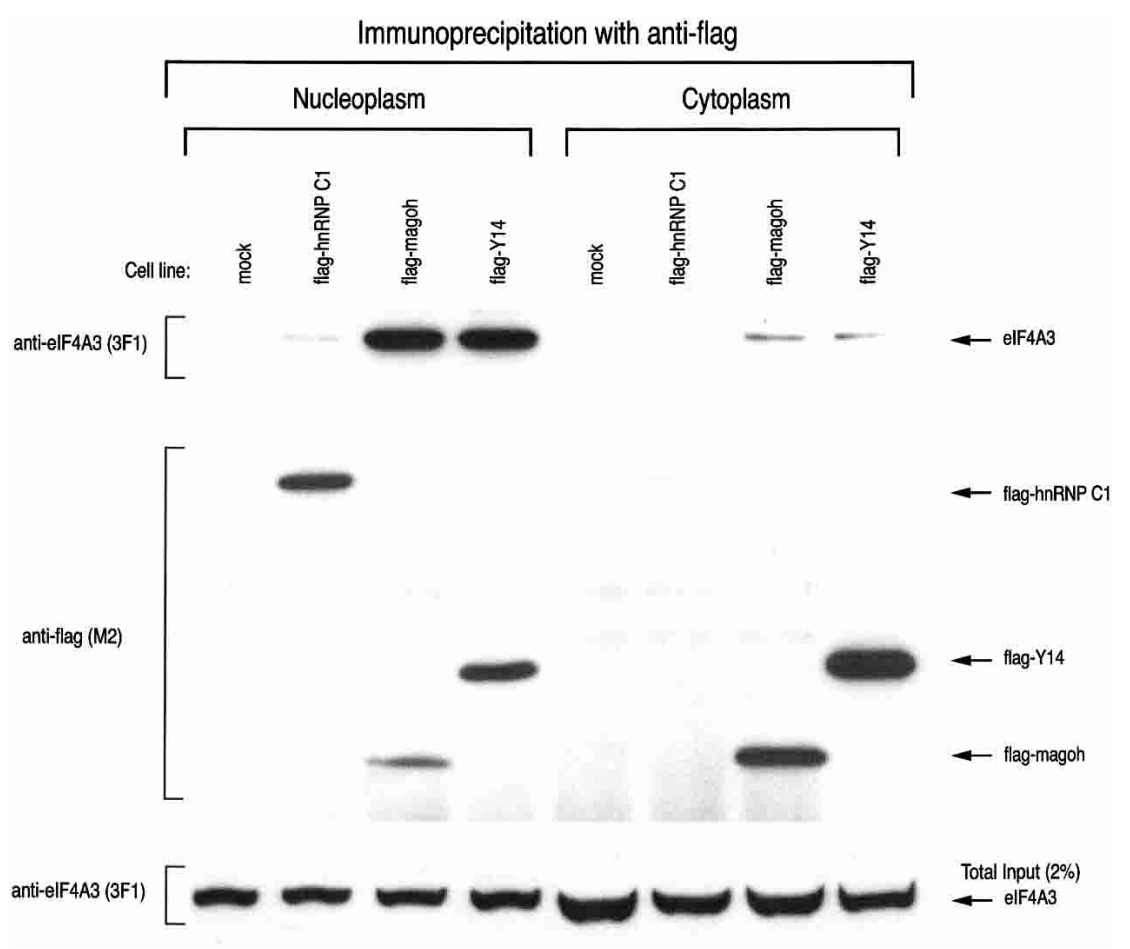

FIGURE 5. eIF4A3 associates with nuclear magoh and Y14 complexes in vivo. Nucleoplasmic (left) and cytoplasmic (right) extracts from parental Tet-On (mock), flag-hnRNP C1, flag-magoh, and flag-Y14 cell lines were incubated with anti-flag antibody beads, and bound proteins were eluted as described in Materials and Methods. Eluted proteins were resolved by SDS-PAGE and analyzed by Western blotting with anti-eIF4A3 antibody (3F1, top panel) and anti-flag antibody (M2, middle panel). Nucleoplasmic and cytoplasmic levels of eIF4A3 in total extracts are shown in the bottom panel and represent $2 \%$ of the amount used for immunoprecipitation. 


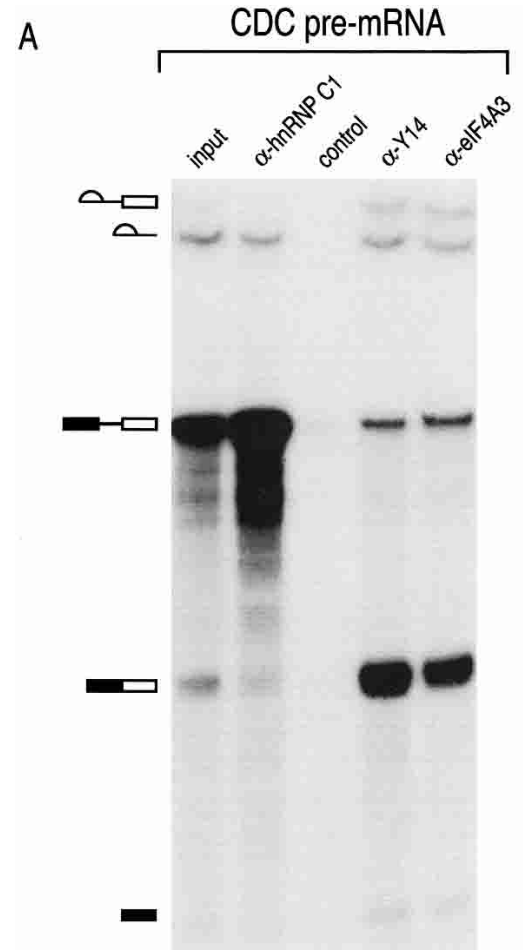

FIGURE 6. eIF4A3 binds spliced but not intronless mRNAs in vitro. $(A)\left[{ }^{32} \mathrm{P}\right]$-labeled CDC pre-mRNA was spliced in total HeLa cell extracts. In vitro splicing reactions were immunoprecipitated with 4F4 ( $\alpha$-hnRNP C1), SP2/0 (control), 4C4 ( $\alpha$-Y14), and 3F1 ( $\alpha$-eIF4A3). Associated RNAs were analyzed on a $6 \%$ polyacrylamide denaturing gel, and revealed by autoradiography. (B) Same as in $A$ except, $\left[{ }^{32} \mathrm{P}\right]$-labeled CDC mRNA was used in this assay. Input represents $5 \%$ of total used in immunoprecipitation experiments. A schematic representation of RNAs is shown on the left.

eIF4A1 and eIF4A2. It was previously shown that eIF4A3 inhibits translation in an in vitro reticulocyte translation system ( $\mathrm{Li}$ et al. 1999). However, nothing is known about the function of eIF4A3 as part of the EJC. eIF4A3 was recently reported to be present in the $\mathrm{B}$ and $\mathrm{C}$ spliceosomal complexes whereas two of the EJC proteins, Y14 and magoh, were only found in the latter (Jurica et al. 2002; Jurica and Moore 2003). Thus, it is possible that in the nucleus, eIF4A3 functions to promote unwinding of secondary structures within pre-mRNA substrates to stimulate splicing and/or facilitate assembly of EJCs on spliced mRNAs.

The observation that eIF4A3 efficiently interacts with TAP and Aly/REF in vitro (Fig. 9) suggests that eIF4A3 might play a role in nuclear mRNA export. TAP, Aly/REF, and UAP56 were previously shown to be important for mRNA export (Zhou et al. 2000; Gatfield et al. 2001). The nucleocytoplasmic transport of mRNAs through nuclear pore complexes (NPCs) is an active, energy-dependent process during which considerable mRNP remodeling, including the removal of several hnRNP and EJC proteins, is thought to occur. Because eIF4A3 is an ATP-dependent RNA helicase, it might contribute to the remodeling and translocation of mRNPs during transit through NPCs. Another DEAD-box RNA helicase, Dbp5, has been implicated in similar processes (Snay-Hodge et al. 1998; Zhao et al. 2002).

Although the step at which eIF4A3 is displaced from the mRNP is unknown, it is possible that it persists on mRNAs into the cytoplasm, as low levels of eIF4A3 were found to associate with Y14-containing complexes in the cytoplasm (Fig. 5). Considering its reported activity as a translation inhibitor (Li et al. 1999), eIF4A3 might inhibit premature or aberrant translation in both the nucleus and the cytoplasm. eIF4A3 was shown to interact with the translation initiation factor eIF4G, although more weakly than the positive effectors of translation, eIF4A1 and eIF4A2. Thus, in addition to directly inhibiting translation initiation along the length of mRNAs, eIF4A3 may also indirectly stimulate translation in the cytoplasm by increasing the local concentration of eIF4G and other initiation factors onto spliced mRNPs. In this model, eIF4A3 would remain associated with mRNPs until it is removed by the ribosome during the first round of translation. This concept also suggests a role for eIF4A3 in NMD. Alternatively, eIF4A3 might be replaced by eIF4A1 or eIF4A2 on the mRNP to stimulate the first round of translation. The discovery of eIF4A3 as a component of EJCs will provide further insight into the role of the EJC in influencing postsplicing processes including translation.

\section{MATERIALS AND METHODS}

\section{Plasmids}

The plasmids used to establish inducible cell lines of flag-hnRNP $\mathrm{C} 1$, flag-magoh, and flag-Y14 were generated by subcloning PCR products containing a flag sequence at the $5^{\prime}$ end into the pTRE vector (Clontech). eIF4A3, eIF4A2, and eIF4A1 cDNAs were isolated by PCR from a HeLa cDNA library. cDNAs were cloned into modified pcDNA3 vectors (Invitrogen) containing either the myctag or the flag-tag sequence at the $5^{\prime}$ end. The eIF4A3 and eIF4A1 cDNAs were cloned into the pGEX-6p-2 vector (Amersham Biosciences, Inc.) for the purification of GST-tagged recombinant proteins, and into the pet28a vector (Novagen) for the purification of His-tagged recombinant proteins.

\section{Generation of stable cell lines}

HeLa Tet-On cells (Clontech) that constitutively express the tetracycline transactivator were cotransfected by the calcium phosphate method with the pTRE plasmids encoding either flag- 


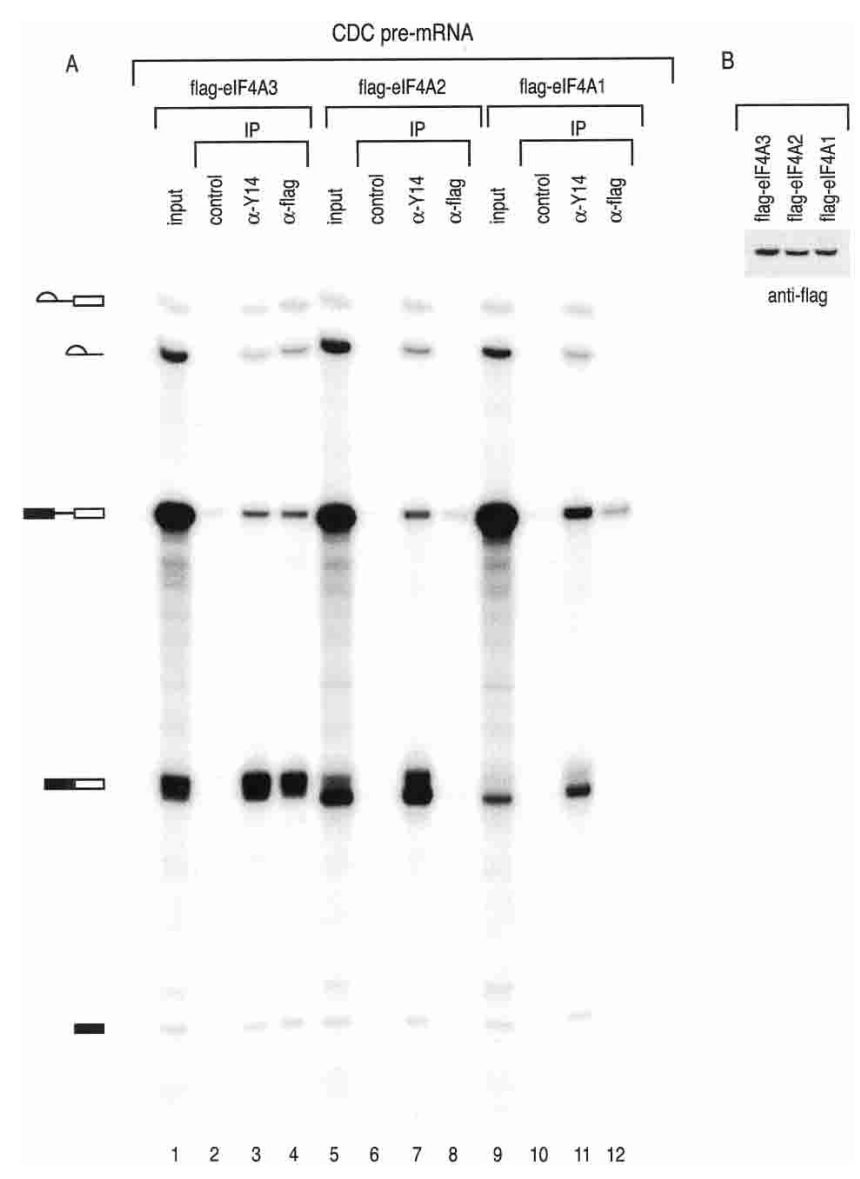

FIGURE 7. eIF4A1 and eIF4A2 do not bind spliced mRNAs in vitro. (A) $\left[{ }^{32} \mathrm{P}\right]$-labeled CDC pre-mRNA was spliced in total extracts from HeLa cells transiently transfected with flag-eIF4A3, flag-eIF4A2, or flag-eIF4A1. Splicing reactions were immunoprecipitated with SP2/0 (control), 4C4 ( $\alpha$-Y14), and M2 ( $\alpha$-flag), and coimmunoprecipitated RNAs were analyzed on a $6 \%$ polyacrylamide denaturing gel. Inputs represent $5 \%$ of total reactions used for immunoprecipitation. A schematic representation of RNAs is shown on the left. (B) Splicing extracts were resolved by SDS-PAGE and analyzed by Western blotting with the anti-flag monoclonal antibody M2.

hnRNP C1, flag-magoh, or flag-Y14 and with a pTK-Hyg plasmid carrying the hygromycin resistance gene for selection. Stable clones were obtained by double selection in the presence of G418 $(100 \mu \mathrm{g} / \mathrm{mL})$ and hygromycin $(200 \mu \mathrm{g} / \mathrm{mL})$. Individual clones were isolated and analyzed by Western blotting for the expression of flag-hnRNP C1, flag-magoh, or flag-Y14 using the anti-flag antibody M2 (Sigma) after induction with doxycycline $(5 \mu \mathrm{g} / \mathrm{mL})$ for 24 h. Stable HeLa Tet-On (parental cell), flag-hnRNPCl, flag-magoh, and flag-Y14 cell lines were cultured in Dulbecco's modified Eagle's medium supplemented with $10 \%$ fetal bovine serum (complete DMEM), G418 (100 $\mu \mathrm{g} / \mathrm{mL})$, and hygromycin $(200 \mu \mathrm{g} / \mathrm{mL})$. HeLa Tet-On cells (control) were cultured in complete DMEM in the presence of G418 $(100 \mu \mathrm{g} / \mathrm{mL})$.

\section{Affinity purification of flag-hnRNP C1, flag-magoh, and flag-Y14 complexes}

Flag-hnRNP C1, flag-magoh, flag-Y14, and HeLa Tet-On cells (control) were grown as described above in the presence of doxy- cycline $(1.25 \mu \mathrm{g} / \mathrm{mL})$ for $24 \mathrm{~h}$. Subcellular fractionation of the induced cell lines was performed as previously described (Siomi et al. 1997). Briefly, cytoplasmic extracts were prepared by resuspending cells in RSB $150(10 \mathrm{mM}$ Tris- $\mathrm{HCl}$ at $\mathrm{pH} 7.4,2.5 \mathrm{mM}$ $\mathrm{MgCl}_{2}, 150 \mathrm{mM} \mathrm{NaCl}$ ) containing $0.05 \%$ digitonin, protease inhibitors (Complete; Roche) and $1 \mathrm{mM}$ DTT. Cells were disrupted by passing through a 27 gauge needle five times, and centrifuged at $3000 \mathrm{~g}$ for $1 \mathrm{~min}$. The supernatant was clarified by centrifugation at $27,000 \mathrm{~g}$ for $10 \mathrm{~min}$ and filtered through a $0.45 \mu \mathrm{m}$ filter. The remaining pellets (after the $3000 \mathrm{~g}$ spin), enriched with nuclei, were resuspended in RSB 150 containing 0.5\% Triton X-100, protease inhibitors (Complete; Roche) and $1 \mathrm{mM}$ DTT. The nuclear fraction was briefly sonicated on ice, centrifuged $27,000 \mathrm{~g}$ for $10 \mathrm{~min}$, and filtered through a $0.45 \mu \mathrm{m}$ filter. Cytoplasmic and nucleoplasmic extracts were incubated with anti-flag antibody beads for $1 \mathrm{~h}$ at $4^{\circ} \mathrm{C}$ for binding. After binding, supernatants were discarded, and beads were washed five times with lysis buffer containing $0.5 \%$ Triton X-100, protease inhibitors (Complete; Roche) and $1 \mathrm{mM}$ DTT. Bound complexes were eluted from the anti-flag beads with 5-10 bed volumes of RBS 100 (10 mM Tris- $\mathrm{HCl}$ at $\mathrm{pH} 7.4,2.5 \mathrm{mM}$ $\mathrm{MgCl}_{2}, 100 \mathrm{mM} \mathrm{NaCl}$ ) containing $300 \mathrm{ng} / \mu \mathrm{L} 3 \mathrm{X}$-flag peptide (Sigma) for $1 \mathrm{~h}$ at $4^{\circ} \mathrm{C}$.

\section{Antibodies, Western blotting and immunofluorescence microscopy}

Mouse anti-eIF4A3 monoclonal antibody 3F1 was prepared by immunizing BALB/c mice with full-length recombinant GSTeIF4A3 as previously described (Kataoka et al. 2000). Nonimmune mouse IgG, SP2/0 (Kataoka et al. 2000), and anti-Y14 antibody 4C4 (Kim et al. 2001b) were previously described. The antimonomethylguanosine cap structure antibody H20 (Bochnig et al. 1987) was a generous gift from Dr. Reinhard Lührmann (Max Planck Institute of Biophysical Chemistry, Department of Cellular Biochemistry, Göttingen, Germany). Anti-flag monoclonal antibody M2 and anti-myc monoclonal antibody 9E10 were purchased from Sigma and Santa Cruz, respectively. Peroxidase-coupled antimouse IgG was purchased from Jackson ImmunoResearch Laboratories. Western blotting and immunofluorescence microscopy were performed as previously described (Siomi et al. 1997).

\section{Protein microsequencing by mass spectrometry}

Protein bands were excised from a silver-stained polyacrylamide gel (Novex mini gel, Invitrogen) and in gel digested with trypsin as described previously (Shevchenko et al. 1996). Tryptic peptides in the supernatant were analyzed by nano-electrospray tandem mass spectrometry using a QSTAR (MDS Sciex) equipped with a nanoelectrospray ion source (MDS Proteomics) as previously described (Wilm et al. 1996). Peptides were identified with comprehensive protein and expressed sequence tag databases using the Protein and Peptide Software Suite (MDS Proteomics). No limitation was imposed on protein molecular weight and species of origin.

\section{In vitro splicing, RNase $\mathrm{H}$ digestion, and immunoprecipitation}

Template preparation, in vitro transcription, and in vitro splicing reactions (with minor modification) were performed as previously 


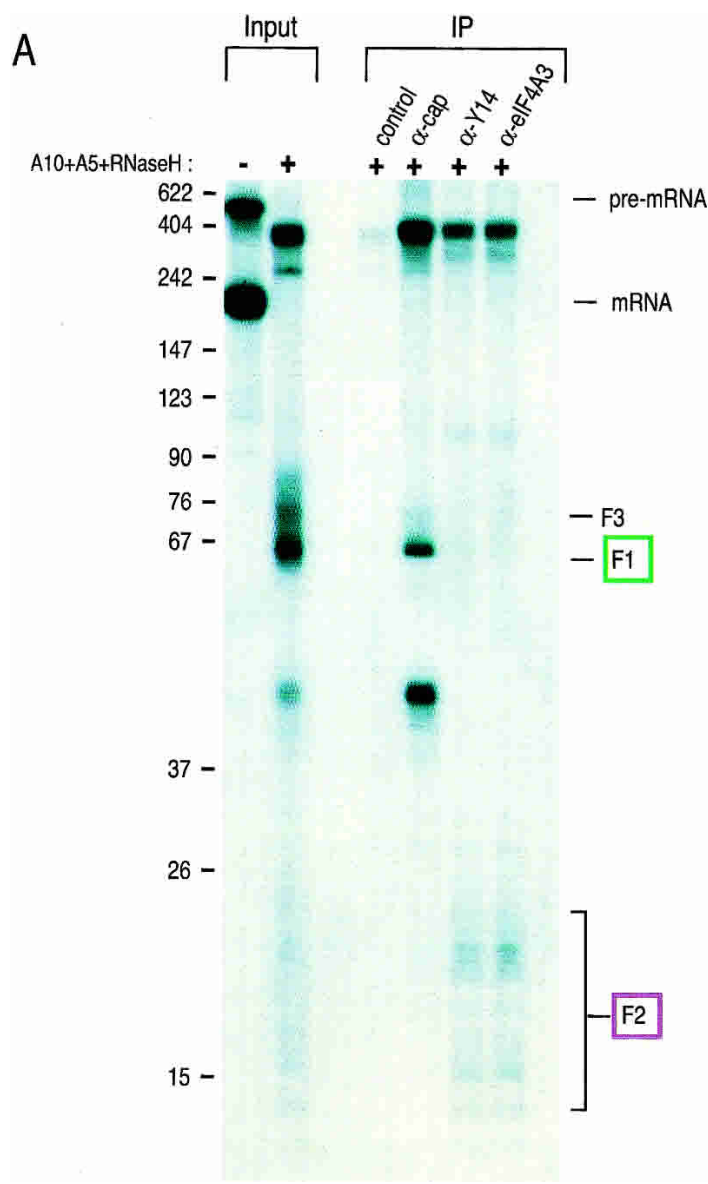

\section{B}

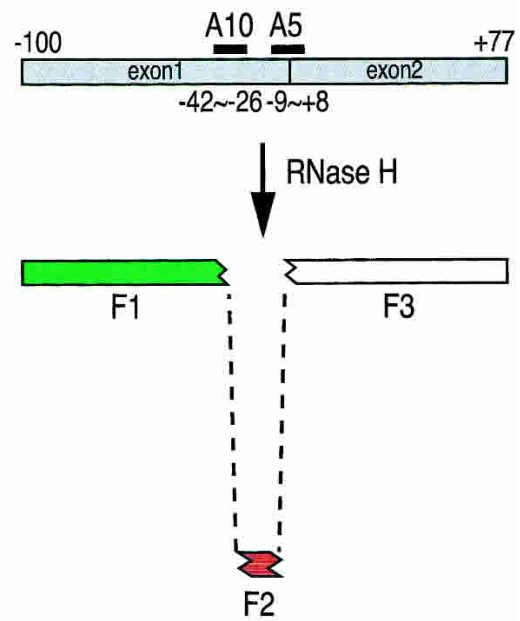

FIGURE 8. eIF4A3 binds at the position of the exon junction complex. (A) $\left[{ }^{32} \mathrm{P}\right]$-labeled Ad2 pre-mRNA was spliced in total HeLa cell extracts, incubated with A5 and A10 oligonucleotides, and subjected to RNase $\mathrm{H}$ digestion. Digested splicing reactions were immunoprecipitated with nonimmune antibody SP2/0 (control), H20 ( $\alpha$-cap), 4C4 ( $\alpha$-Y14), and 3F1 ( $\alpha$-eIF4A3). Coimmunoprecipitated RNA fragments were isolated and analyzed on $10 \%$ polyacrylamide denaturing gel. Inputs represent $5 \%$ of total reactions used for immunoprecipitation. (B) Schematic representation of the RNA fragments generated by RNase H cleavage of spliced Ad2 mRNA. The fragment associated with eIF4A3 is shown in red and the $5^{\prime}$ most fragment immunoprecipitated with the anti-cap antibody is shown in green.

described (Kataoka et al. 2001; Kataoka and Dreyfuss, 2003). Briefly, HeLa cells or HeLa cells transfected with flag-pcDNA3 (control), flag-eIF4A3, flag-eIF4A2, or flag-eIF4A1 were resuspended in Buffer $\mathrm{D}^{\prime}$ (20 mM HEPES-KOH at $\mathrm{pH}$ 7.9, $100 \mathrm{mM}$
KCL, $0.2 \mathrm{mM}$ EDTA). The cells were disrupted by sonication on ice and centrifuged at $27,000 \mathrm{~g}$ for $15 \mathrm{~min}$. The supernatant (Total Hela cell splicing extract) was stored at $-80^{\circ} \mathrm{C}$ until used in splicing reactions. A $40-\mu \mathrm{L}$ splicing reaction contained $16 \mu \mathrm{L}$ of $\mathrm{HeLa}$
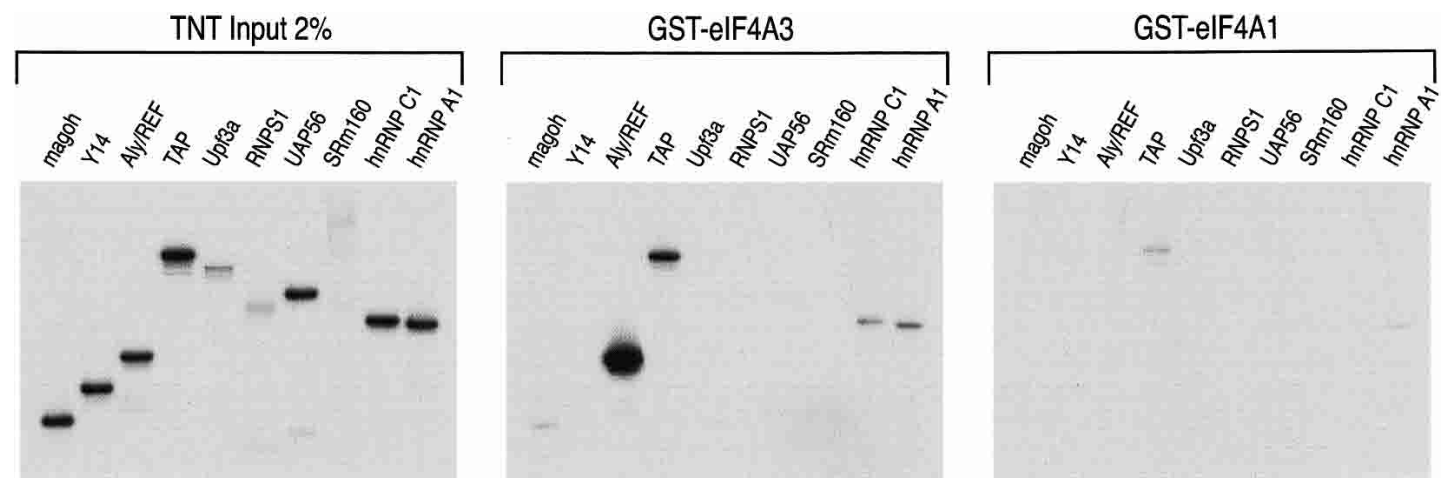

FIGURE 9. eIF4A3 binds TAP and Aly/REF in vitro. The indicated proteins were produced by in vitro transcription and translation in reticulocyte lysate in the presence of $\left[{ }^{35} \mathrm{~S}\right]$ methionine, and incubated with $5 \mu \mathrm{g}$ of purified recombinant GST-eIF4A3 (middle panel) or GST-eIF4A1 (right panel) coupled to glutathione beads. Proteins bound to GST-eIF4A3 or GST-eIF4A1 were resolved by SDS-PAGE and visualized by fluorography. Input represents $2 \%$ of the in vitro translated reaction used for binding (left panel). 
total cell splicing extracts and $4 \mu \mathrm{L}$ of $10 \times$ SP buffer (Pellizzoni et al. 1998). RNase $H$ digestion with $A 5$ and A10 oligonucleotides and immunoprecipitation were performed as previously described (Hanamura et al. 1998; Kim et al. 2001b).

\section{In vitro protein binding experiment}

All $\left[{ }^{35} \mathrm{~S}\right]$ methionine-labeled proteins were produced in vitro using a TNT-coupled rabbit reticulocyte extract system (Promega) according to the manufacturer's protocol. All proteins shown in Figure 9 were expressed from pET28a with a His tag except for RNPS1 and SRm160, which were expressed from pcDNA3 with a flag-tag. Ten microliters of the in vitro translated products were added to $5 \mu \mathrm{g}$ of GST-fusion proteins coupled to glutathione beads in the binding buffer $\left(10 \mathrm{mM}\right.$ Tris- $\mathrm{HCl}$ at $\mathrm{pH} 7.4,2.5 \mathrm{mM} \mathrm{MgCl}_{2}$, $100 \mathrm{mM} \mathrm{NaCl}, 0.5 \mathrm{mM}$ DTT, 0.1\% NP40) and mixed for $1 \mathrm{~h}$ at $4^{\circ} \mathrm{C}$. After binding, beads were washed five times with the same buffer and bound proteins eluted with SDS-PAGE sample buffer and resolved by SDS-PAGE and detected by autoradiography.

\section{ACKNOWLEDGMENTS}

We are grateful to members of our laboratory for stimulating discussions, critical reading, and comments on this manuscript, especially to Drs. Jeongsik Yong, Daniel Battle, Jin Wang, and Lili Wan. We thank Hai Sheng, Robert Olszewski, and Robert Perkinson for technical assistance. We also thank Gina Daly for secretarial assistance. This work was supported by grants from the Canadian Institute of Health Research and from the National Institutes of Health, and by the Association Française contre les Myopathies (AFM). G.D. is an Investigator of the Howard Hughes Medical Institute.

The publication costs of this article were defrayed in part by payment of page charges. This article must therefore be hereby marked "advertisement" in accordance with 18 USC section 1734 solely to indicate this fact.

Received November 13, 2003; accepted November 19, 2003.

\section{REFERENCES}

Blencowe, B.J., Issner, R., Nickerson, J.A., and Sharp, P.A. 1998. A coactivator of pre-mRNA splicing. Genes \& Dev. 12: 996-1009.

Bochnig, P., Reuter, R., Bringmann, P., and Lührmann, R. 1987. A monoclonal antibody against 2,2,7-trimethylguanosine that reacts with intact, class $\mathrm{U}$, small nuclear ribonucleoproteins as well as with 7-methylguanosine-capped RNAs. Eur. J. Biochem. 168: 461467.

Choi, Y.D. and Dreyfuss, G. 1984. Isolation of the heterogeneous nuclear RNA-ribonucleoprotein complex (hnRNP): A unique supramolecular assembly. Proc. Natl. Acad. Sci. 81: 7471-7475.

Dostie, J. and Dreyfuss, G. 2002. Translation is required to remove Y14 from mRNAs in the cytoplasm. Curr. Biol. 12: 1060-1067.

Dreyfuss, G., Matunis, M.J., Pinol-Roma, S., and Burd, C.G. 1993. hnRNP proteins and the biogenesis of mRNA. Annu. Rev. Biochem. 62: $289-321$.

Dreyfuss, G., Kim, V.N., and Kataoka, N. 2002. Messenger-RNA-binding proteins and the messages they carry. Nat. Rev. Mol. Cell. Biol. 3: $195-205$.

Gatfield, D., Le Hir, H., Schmitt, C., Braun, I.C., Kocher, T., Wilm, M., and Izaurralde, E. 2001. The DExH/D box protein HEL/UAP56 is essential for mRNA nuclear export in Drosophila. Curr. Biol. 11: 1716-1721.

Gehring, N.H., Neu-Yilik, G., Schell, T., Hentze, M.W., and Kulozik, A.E. 2003. Y14 and hUpf3b form an NMD-activating complex. Mol. Cell. 11: 939-949.

Hachet, O. and Ephrussi, A. 2001. Drosophila Y14 shuttles to the posterior of the oocyte and is required for oskar mRNA transport. Curr. Biol. 11: 1666-1674.

Hanamura, A., Caceres, J.F., Mayeda, A., Franza Jr., B.R., and Krainer, A.R. 1998. Regulated tissue-specific expression of antagonistic premRNA splicing factors. RNA 4: 430-444.

Holzmann, K., Gerner, C., Poltl, A., Schafer, R., Obrist, P., Ensinger, C., Grimm, R., and Sauermann, G. 2000. A human common nuclear matrix protein homologous to eukaryotic translation initiation factor 4A. Biochem. Biophys. Res. Commun. 267: 339-344.

Jurica, M.S. and Moore, M.J. 2003. Pre-mRNA splicing: Awash in a sea of proteins. Mol. Cell. 12: 5-14.

Jurica, M.S., Licklider, L.J., Gygi, S.R., Grigorieff, N., and Moore, M.J. 2002. Purification and characterization of native spliceosomes suitable for three-dimensional structural analysis. RNA 8: 426-439.

Kataoka, N. and Dreyfuss, G. 2003. A simple whole-cell lysate system for in vitro splicing reveals a stepwise-assembly of the exon-exon junction complex. J. Biol. Chem. (in press).

Kataoka, N., Yong, J., Kim, V.N., Velazquez, F., Perkinson, R.A., Wang, F., and Dreyfuss, G. 2000. Pre-mRNA splicing imprints mRNA in the nucleus with a novel RNA-binding protein that persists in the cytoplasm. Mol. Cell 6: 673-682.

Kataoka, N., Diem, M.D., Kim, V.N., Yong, J., and Dreyfuss, G. 2001. Magoh, a human homolog of Drosophila mago nashi protein, is a component of the splicing-dependent exon-exon junction complex. EMBO J. 20: 6424-6433.

Kim, V.N., Kataoka, N., and Dreyfuss, G. 2001a. Role of the nonsensemediated decay factor hUpf3 in the splicing-dependent exon-exon junction complex. Science 293: 1832-1836.

Kim, V.N., Yong, J., Kataoka, N., Abel, L., Diem, M.D., and Dreyfuss, G. 2001b. The Y14 protein communicates to the cytoplasm the position of exon-exon junctions. EMBO J. 20: 2062-2068.

Le Hir, H., Izaurralde, E., Maquat, L.E., and Moore, M.J. 2000a. The spliceosome deposits multiple proteins 20-24 nucleotides upstream of mRNA exon-exon junctions. EMBO J. 19: 6860-6869.

Le Hir, H., Moore, M.J., and Maquat, L.E. 2000b. Pre-mRNA splicing alters mRNP composition: Evidence for stable association of proteins at exon-exon junctions. Genes \& Dev. 14: 1098-1108.

Le Hir, H., Gatfield, D., Braun, I.C., Forler, D., and Izaurralde, E. 2001. The protein Mago provides a link between splicing and mRNA localization. EMBO Rep. 2: 1119-1124.

Li, Q., Imataka, H., Morino, S., Rogers Jr., G.W., Richter-Cook, N.J., Merrick, W.C., and Sonenberg, N. 1999. Eukaryotic translation initiation factor 4AIII (eIF4AIII) is functionally distinct from eIF4AI and eIF4AII. Mol. Cell. Biol. 19: 7336-7346.

Luo, M.J. and Reed, R. 1999. Splicing is required for rapid and efficient mRNA export in metazoans. Proc. Natl. Acad. Sci. 96: 14937-14942.

Luo, M.L., Zhou, Z., Magni, K., Christoforides, C., Rappsilber, J., Mann, M., and Reed, R. 2001. Pre-mRNA splicing and mRNA export linked by direct interactions between UAP56 and Aly. Nature 413: 644-647.

Lykke-Andersen, J., Shu, M.D., and Steitz, J.A. 2000. Human Upf proteins target an mRNA for nonsense-mediated decay when bound downstream of a termination codon. Cell 103: 1121-1131.

. 2001. Communication of the position of exon-exon junctions to the mRNA surveillance machinery by the protein RNPS1. Science 293: 1836-1839.

Matsumoto, K., Wassarman, K.M., and Wolffe, A.P. 1998. Nuclear history of a pre-mRNA determines the translational activity of cytoplasmic mRNA. EMBO J. 17: 2107-2121.

Mayeda, A., Badolato, J., Kobayashi, R., Zhang, M.Q., Gardiner, E.M., and Krainer, A.R. 1999. Purification and characterization of human RNPS1: A general activator of pre-mRNA splicing. EMBO J. 18: $4560-4570$. 
Mohr, S.E., Dillon, S.T., and Boswell, R.E. 2001. The RNA-binding protein Tsunagi interacts with Mago Nashi to establish polarity and localize oskar mRNA during Drosophila oogenesis. Genes \& Dev. 15: 2886-2899.

Newmark, P.A. and Boswell, R.E. 1994. The mago nashi locus encodes an essential product required for germ plasm assembly in Drosophila. Development 120: 1303-1313.

Nott, A., Meislin, S.H., and Moore, M.J. 2003. A quantitative analysis of intron effects on mammalian gene expression. RNA 9: 607-617.

Ohno, M., Sakamoto, H., and Shimura, Y. 1987. Preferential excision of the $5^{\prime}$ proximal intron from mRNA precursors with two introns as mediated by the cap structure. Proc. Natl. Acad. Sci. 84: 51875191.

Pellizzoni, L., Kataoka, N., Charroux, B., and Dreyfuss, G. 1998. A novel function for SMN, the spinal muscular atrophy disease gene product, in pre-mRNA splicing. Cell 95: 615-624.

Shevchenko, A., Wilm, M., Vorm, O., and Mann, M. 1996. Mass spectrometric sequencing of proteins silver-stained polyacrylamide gels. Anal. Chem. 68: 850-858.
Siomi, M.C., Eder, P.S., Kataoka, N., Wan, L., Liu, Q., and Dreyfuss, G. 1997. Transportin-mediated nuclear import of heterogeneous nuclear RNP proteins. J. Cell. Biol. 138: 1181-1192.

Snay-Hodge, C.A., Colot, H.V., Goldstein, A.L., and Cole, C.N. 1998. Dbp5p/Rat8p is a yeast nuclear pore-associated DEAD-box protein essential for RNA export. EMBO J. 17: 2663-2676.

Wiegand, H.L., Lu, S., and Cullen, B.R. 2003. Exon junction complexes mediate the enhancing effect of splicing on mRNA expression. Proc. Natl. Acad. Sci. 100: 11327-11332.

Wilm, M., Shevchenko, A., Houthaeve, T., Breit, S., Schweigerer, L., Fotsis, T., and Mann, M. 1996. Femtomole sequencing of proteins from polyacrylamide gels by nano-electrospray mass spectrometry. Nature 379: 466-469.

Zhao, J., Jin, S.B., Bjorkroth, B., Wieslander, L., and Daneholt, B. 2002. The mRNA export factor Dbp5 is associated with Balbiani ring mRNP from gene to cytoplasm. EMBO J. 21: 1177-1187.

Zhou, Z., Luo, M.J., Straesser, K., Katahira, J., Hurt, E., and Reed, R. 2000. The protein Aly links pre-messenger-RNA splicing to nuclear export in metazoans. Nature 407: 401-405. 

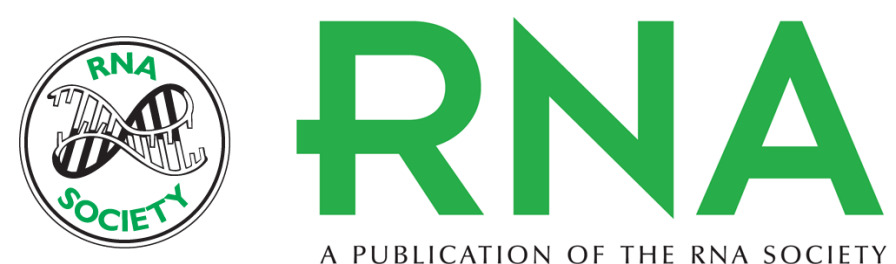

A PUBLICATION OF THE RNA SOCIETY

\section{elF4A3 is a novel component of the exon junction complex}

CHIA C. CHAN, JOSÉE DOSTIE, MICHAEL D. DIEM, et al.

RNA 2004 10: 200-209

References This article cites 39 articles, 23 of which can be accessed free at:

http://rnajournal.cshlp.org/content/10/2/200.full.html\#ref-list-1

License

Email Alerting Receive free email alerts when new articles cite this article - sign up in the box at the Service top right corner of the article or click here. 